
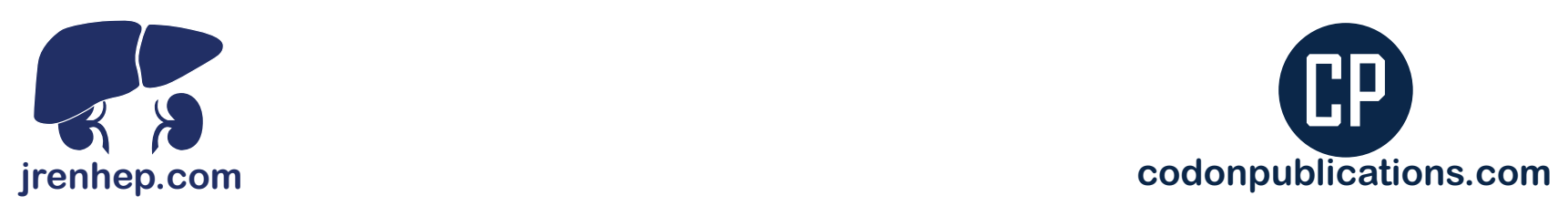

REVIEW ARTICLE

\title{
Hepatic Venous Outflow Obstruction: Suggestion of a New Classification
}

\author{
Santosh Man Shrestha \\ Liver Foundation Nepal, Sitapaela Height, Kathmandu, Nepal
}

\begin{abstract}
Hepatic venous outflow obstruction (HVOO) is common in developing countries. It is a serious condition that clinically manifests with ascites from sinusoidal hypertension, and carries the risk of high mortality or development of liver cirrhosis. In the past, the eponym Budd-Chiari Syndrome (BCS) was used synonymously for HVOO. In the West, hepatic vein (HV) thrombosis caused by prothrombotic disorders is the main cause of HVOO. In the East, obliterative disease of hepatic portion of inferior vena cava induced by bacterial infection, now renamed hepatic vena cava syndrome, is the common cause of HVOO. These two diseases with different etiology, epidemiology, and natural history are at present grouped together under BCS causing much confusion. Sinusoidal obstruction syndrome, another important cause of HVOO at the level of the sinusoid and terminal HV, was left out in the classification of HVOO. In this article, the pathophysiology of sinusoidal hypertension is described, the term BCS is redefined, and a new classification of HVOO is suggested.
\end{abstract}

Keywords: ascites; bacterial infection; Budd-Chiari syndrome; hepatic vena cava syndrome; liver cirrhosis; sinusoidal obstruction syndrome

Received: 01 March 2017; Accepted after revision: 26 June 2017; Published: 31 July 2017.

Author for correspondence: Santosh Man Shrestha, Liver Foundation Nepal, Sitapaela Height, Nagarjun Municipality 2, PO Box: C/O Pradeep Kazi Tamrakar, PO Box \# 13273, Kathmandu, Nepal. Email: smshrestha1938@gmail.com

How to cite: Shrestha SM. Hepatic venous outflow obstruction: Suggestion of a new classification. J Ren Hepat Disord 2017;1(2):41-51.

DOI: http://dx.doi.org/10.15586/jrenhep.2017.13

Copyright: Shrestha SM.

License: This open access article is licensed under Creative Commons Attribution 4.0 International (CC BY 4.0). http://creativecommons.org/licenses/by/4.0

\section{Introduction}

Liver is a highly vascular organ with dual blood supply from hepatic artery and portal vein (PV). Normal hepatic blood flow is about $1500 \mathrm{~mL} / \mathrm{min}$. PV blood contributes approximately $70 \%$ of the flow and $50 \%$ of the oxygen consumed by liver. Blood from hepatic artery at about $100 \mathrm{~mm} \mathrm{Hg}$ pressure and PV at about $10 \mathrm{~mm} \mathrm{Hg}$ pressure mixes in the hepatic sinusoid. In contrast to other capillaries whose endothelial linings are continuous, the sinusoidal capillaries are lined by discontinuous layer of endothelium that has pores of about $30-50 \mathrm{~nm}$ in size called fenestrae grouped into sieve plates (1). The liver sinusoids are also noted by the absence of a demonstrable basement lamina. Thus, the endothelium is highly permeable and largely supported by a carpet-like pile formed by liver cell microvilli separated by the space of Disse. Hepatic microcirculation is characterized by low outflow resistance. The ratio of pre- to post-capillary resistance in skeletal muscle is 4:1 compared to $49: 1$ in the liver, which results in a very low outflow resistance (2). Maintenance of low sinusoidal pressure is important for normal hepatic function. This is helped by another unique interrelationship between the sinusoidal pressure and the hepatic arterial flow. Increase in sinusoidal pressure results in reflex decrease in hepatic arterial flow (3). Thus, despite increase in portal venous flow during digestion, the sinusoidal pressure is maintained low. The size of the pore in hepatic sieve plate is just 
right at normal sinusoidal pressure to maintain an oncotic gradient that prevents loss of protein into interstitial space. The anatomy of hepatic microcirculation is adjusted to allow the hepatocytes a close contact with the incoming PV blood rich in nutrients and hormones, a process that facilitates liver to play its role in body metabolism.

\section{Clinical manifestation of HVOO}

Sinusoidal blood that drains into terminal hepatic vein (HV) is collected in lobular and sublobular veins that join to form medium-sized veins. Medium-sized veins join to form large HVs. Three large and nearly 20 small HVs drain the liver blood into inferior vena cava (IVC), which carries it to the right atrium of the heart. Hepatic venous outflow obstruction (HVOO) may occur at the level of the sinusoids, at HVs, or IVC at the HV outlets. Orifices of large HVs are considered by some as part of the IVC system (4). HVs have no valve and any increase in IVC pressure is directly transmitted to the liver. Thus, cardiac condition such as constrictive pericarditis mimics HVOO (5).

The clinical manifestation of HVOO largely depends on the extent and speed of obstruction, its cause, and the development of compensatory mechanisms. Obstruction of a few medium-sized HVs or a large HV may not cause any symptom. Insidiously developing multiple $\mathrm{HV}$ obstruction that allows development of collaterals also remains asymptomatic. HV obstructions thus may largely remain asymptomatic for variable period, till a large part of hepatic outflow tract is obstructed, resulting in sudden increase in sinusoidal pressure. Sinusoidal hypertension manifests clinically as ascites. Sinusoidal hypertension and ascites occur and reoccur at any time in the course of the diseases of HV and IVC.

\section{Pathophysiology of sinusoidal hypertension}

\section{Development of ascites}

HVOO that results in sinusoidal hypertension (Figure 1) causes sinusoidal dilatation and drop in the intra-hepatic blood flow. Because of the unique anatomic feature of the hepatic sinusoid, sinusoidal hypertension is followed by rapid flow of protein-rich fluid into the space of Disse. The protein concentration in the interstitium approaches that of plasma with loss of oncotic gradient between the blood and space of Disse. The fluid that enters the space of Disse is removed by the lymphatics. Increased formation of lymph occurs. When it exceeds the draining capacity of the lymphatics, it oozes out into the peritoneal cavity. Droplets of lymph oozing from the dilated lymphatics on the surface of the liver, labeled as "weeping liver," had been observed during laparoscopy and surgery. Fluid that enters the abdomen is absorbed by the lymphatics of the peritoneal cavity, principally by diaphragmatic lymphatics. The amount of ascites that accumulates reflects a balance between rates of formation and absorption. The rate at which ascites is formed is determined by the sinusoidal pressure, the permeability characteristic of hepatic sinusoids, and the capacity of lymphatics to drain. The rate at which ascitic fluid is removed is determined by the nature of the peritoneal membrane and intraperitoneal pressure. The thickening of the peritoneal membrane slows the rate of absorption of ascitic fluid. Ascites in hepatic vena cava syndrome (HVCS) is associated with bacterial peritonitis resulting in thickened peritoneum (6). Slow rate of removal of ascitic fluid from peritoneal cavity, combined with persistence of bacterial infection, leads to development of chronic peritonitis in HVC (7).

\section{Sodium retention by kidneys}

Ligation of IVC immediately above HV opening is followed by increase in sinusoidal pressure and development of ascites. Levy and Wexler (8) observed that dogs with lowgrade caval obstruction developed sodium retention which could be prevented by subjecting the animal to complete hepatic denervation before caval ligation. In dogs with high caval obstruction and ascites mobilized by peritoneovenous shunt, hepatic denervation resulted in normal sodium balance despite high sodium intake. In contrast, non-denervated animals with high-grade caval obstruction and a peritoneovenous shunt developed positive sodium balance irrespective of their sodium intake and developed anasarca with highsodium diet. The stimulus to sodium retention by kidneys arises in sinusoidal wall and is mediated by hepatic baroreceptors. Sodium retention further aggravates the ascites, and is responsible for symptoms like puffy face and swelling of hands and legs in these patients.

\section{Liver damage in sinusoidal hypertension}

Sinusoidal hypertension with associated reflex reduction of hepatic arterial inflow results in centrilobular ischemic liver damage. Liver biopsy in patients with acute HVOO shows thickened or obstructed centrilobular vein wall, sinusoidal dilatation, centrilobular hemorrhagic infiltration, and atrophy of hepatic cord. The extinct liver parenchyma is replaced by fibrosis within a few weeks. Regenerative activity of the unaffected liver cells around portal tract, as indicated by liver cells that are bigger and often arranged in double layer, attempts to maintain normal parenchymal function. The process ultimately leads to the development of veno-centric liver cirrhosis (LC) with dense fibrosis largely confined to peri-venular area. Patients with HVCS often have associated endophlebitis of medium-sized HVs and PVs. The associated ischemic liver damage eventually results in development of veno-portal type of cirrhosis (9-11). Development of LC within 3-9 months of liver biopsy for acute diseases has been documented in patients with sinusoidal obstruction syndrome (SOS) (12, 13), Budd-Chiari syndrome (BCS) (14), and HVCS (11). Thus, unlike in liver disease due to alcohol or chronic hepatitis B or hepatitis C where it takes 20-25 years of exposure for the agent for LC to develop, in 


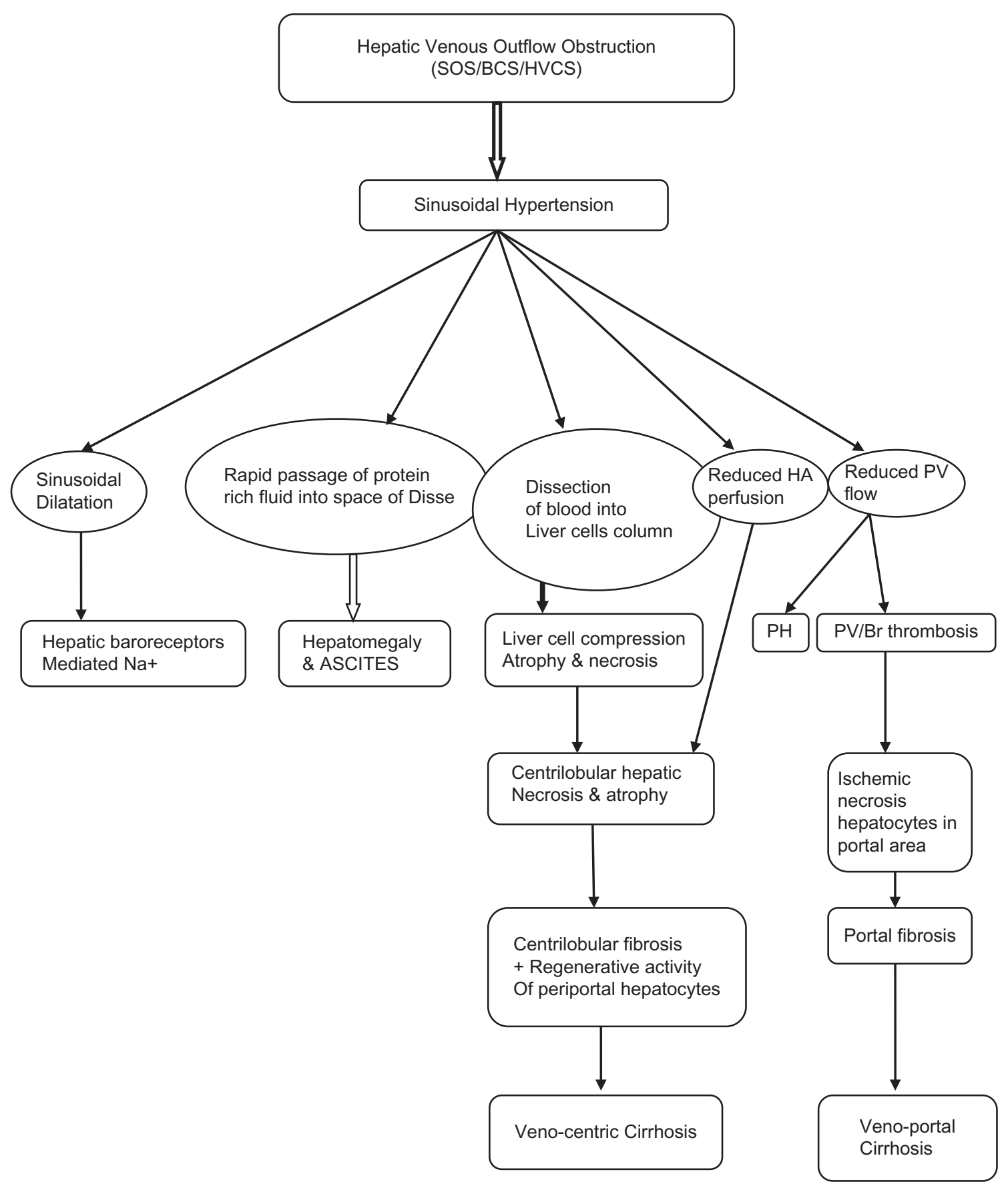

Figure 1. Pathophysiology of sinusoidal hypertension.

sinusoidal hypertension, cirrhosis develops rapidly. HVCSinduced LC is characterized by many distinct clinical, ultrasonography, and color Doppler (US/CD) features (15).

Leopold et al. (16), based on histological study of biopsies and postmortem tissue from cases with HVOO, have put forth evidence that an early event in sinusoidal hypertension is the exit of blood cells from sinusoid into space of Disse where they become intermingled with the cells of liver plates.
Blood cells dissecting and compressing the columns of liver cell plates result in atrophy and necrosis of hepatocytes (16). Similar changes were also reported in the experimental HV ligation (17) and in patients with heart failure (18). Sinusoids are frequently dilated and empty in the biopsies but are seen engorged with blood cells in the postmortem livers. Sinusoidal congestion seen in postmortem histology is interpreted as agonal change or postmortem reflux from 
the great veins. Effects in liver due to HV occlusion and heart failure are similar. Sherlock who studied 41 liver biopsies from cases of clinical heart failure had mentioned of the agonal and postmortem changes that may aggravate the degree of parenchymal damage present during lifetime (19).

Sinusoidal hypertension is associated with decreased PV inflow. Slow PV flow combined with presence of infection in HVCS and hypercoagulable state in BCS results in thrombophlebitis or thrombosis of PV and its branches. Secondary thrombosis of PV in HVCS was described by Chiari (20). Parker observed this complication in $20 \%$ of the cases (21). Tanaka and Wanless, in their study of 15 resected livers from patients with $\mathrm{BCS}$, detected severe $\mathrm{PV}$ obstruction by thrombosis and presence of veno-portal cirrhosis in six livers, and moderate PV obstruction in another six livers, that showed mixed veno-centric and veno-portal cirrhosis (22). Similarly, Kage et al. reported fibrosis of portal tract in livers with congestive fibrosis and congestive cirrhosis due to HVCS (23). Diffuse, thickened echoic wall of PV and its branches with occasional thrombosed branches are frequently observed in US/CD examination of patients with HVCS. Whereas HVCS is a common cause of PV thrombosis in Nepal, in India, it was reported only in patients with LC and HCC related to prothrombotic conditions (24).

The liver damage in sinusoidal hypertension due to HVOO is thus not limited to acute congestive changes around terminal HVs as was previously considered, but different mechanisms of liver parenchymal damage operate in patients. These include dissection of blood into liver trabeculae, ischemic injury due to occlusion of $\mathrm{HV}$ and $\mathrm{PV}$, and ischemic injury of sinusoidal linings by release of free radicals (25). The outcome of liver damage, however, is influenced by compensatory mechanisms that come into play: the regenerative activity of the unaffected hepatocytes especially around portal tract, and the development of collaterals between obstructed and patent veins in and around the liver.

\section{Present classification of HVOO}

At present, the eponym BCS is used synonymously for HVOO (26-29). In the past, it had been used for various entities, as some used it for thrombosis of large HVs, others for both thrombotic and non-thrombotic lesions of large HVs and IVC between the liver and right atrium, and a few used it even when the obstruction was in the right atrium. As the term "BCS" became ambiguous that neither identifies the morphology nor the site of obstruction nor the etiology of the disease, Ludwig et al in 1990 suggested dropping the use of the term (4) which was supported by Okuda (30). In their original papers, Budd described three cases of hepatic vein thrombosis (HVT) subsequent to abscess-induced phlebitis which he ascribed to sepsis and alcoholism or syphilis (31), and Chiari (1898) described another three cases of "phlebitis obliterans" where microscopic lesion had extended to adjacent segment of IVC (20). Similar cases were described by
Raynaud in 1827 (32) before Budd, and by many including Wilks (33) and Osler (34) before Chiari. Justification for the continued use of the eponym thus appears tenacious. However, an international panel from Europe in 2003 advocated retaining $\mathrm{BCS}$ because of its long usage and defined it as HVOO wherever the level or mechanism of obstruction, with exclusion of SOS and cardiac and pericardial diseases (26). BCS was divided into primary BCS when related to a primarily venous disease (thrombosis or phlebitis), and secondary BCS when related to compression or invasion by a lesion originating outside the vein (benign or malignant tumor, abscess or cyst). Further classifications according to its location (small HVs, large HVs, IVC, and combination obstruction of large HVs and IVC) have been suggested. And it has become a common practice to classify HVOO based on the level of obstruction into HV block, IVC block, and combined HV and IVC block (35-38). Classifying HVOO on the basis of the site of obstruction is not helpful as the site of obstruction in the HVOO tract does not differentiate primary diseases of HVOO and it does not influence the management. In BCS, lesions develop not only in large HVs but also in medium, small, and terminal HVs $(21,22)$ and now it appears even at the level of sinusoid. Similarly, in HVCS, besides primary lesion in IVC, lesions develop at different levels in HVs as in BCS (23). Patients or livers, both in BCS and HVCS have multiple lesions not only at different levels in HVs but also in PV and its branches (21-23). There was also a suggestion to classify HVOO as due to thrombotic and non-thrombotic lesions; in non-thrombotic group, webs and membrane were included with tumor or other obstructive anomalies (4). It is now well recognized that not only webs, membrane, and stenosis but even calcification of the lesions in HV and IVC is the sequel of initial thrombosis or thrombophlebitis (21-23), and their presence indicates the duration of the disease process.

HVOO is rare in the West where it is predominantly due to HVT caused by a combination of inherited and acquired thrombogenic conditions of which myeloproliferative disorder is the common $(26,39,40)$. HVOO is common in the East where it is an important cause of portal hypertension $(41,42)$, ascites (6), and $\operatorname{LC}(11,15,43)$, and is predominantly due to the disease of the hepatic portion of IVC (43-59). Okuda and colleagues in 1998 established this disease as a distinct clinical entity (60). The epidemiology, etiology, and clinical course of the disease of IVC are different from HVT (61) and it is now renamed HVCS and a new concept of pathogenesis of the disease based on bacterial infection etiology has recently been put forth (7). In India, both HVCS and HVT occur. In practice, Western investigators had been using the term "BCS" to mean HVT due to thrombogenic conditions, whereas investigators in the East used it for HVCS and HVT. Vascular surgeons in the East used it for HVCS $(38,59)$. The term "BCS" thus continued to be used by different people to mean different things. Interpretation of the results of the studies and assessment of prognosis 
and treatment of BCS from different centers are thus not comparable. Inclusion of HVT and HVCS together under BCS has been a source of confusion that resulted in patients from developing countries with HVCS subjected to costly investigations for thrombotic disorders. To avoid these confusions, need is felt to redefine the term "BCS" and suggest a meaningful classification of HVOO.

\section{Proposed new classification of HVOO}

- The term "BCS", instead of using it synonymously with $\mathrm{HVOO}$, is used to indicate only the prothrombotic disorders-induced thrombosis of $\mathrm{HVs}$ or IVC as was used by Valla (14).

- HVCS, bacterial infection-induced thrombotic or nonthrombotic obstruction of IVC at or near the HV outlet, is recognized as a separate disease entity and not clubbed together with prothrombotic conditions-induced HVT.

- SOS, non-thrombotic obstruction at the level of sinusoid caused by pyrrolizidine alkaloid or myeloablative therapy which was left out of classification of HVOO, is included in it.

- SOS, BCS, and HVCS that originates from the venous wall or the venous lumen of HV and IVC near HV outlet are considered primary diseases of HVOO (Figure 2).

- HVOO is considered secondary when it is caused by compression or invasion of $\mathrm{HV}$ or hepatic portion of the IVC by lesion arising outside the vein, such as tumor, abscess, or cyst. A brief account of the three primary diseases of HVOO is given in Table 1.

\section{Primary diseases of HVOO \\ Sinusoidal obstruction syndrome}

This disease was first described in South Africa in 1920 in a family who developed cirrhosis with ascites after eating bread made from wheat contaminated with seeds of Senecio. Brass and colleagues later reported similar non-portal-type cirrhosis among inhabitants of Jamaica who drank herbal tea containing pyrrolizidine alkaloid (62) and named it veno-occlusive disease (VOD). The disease had occurred in the former Soviet Union (63). From 1975 to 1977, three outbreaks of the disease were reported from South Asia, two from India, and one from Afghanistan (64-66). Until the advent of chemotherapy in 1950 , ingestion of herbal teas or food sources contaminated with pyrrolizidine alkaloids was the only cause of VOD. Later, the disease was reported among patients receiving long-term immunosuppressant after renal or liver transplantations (67) and in patients with bone marrow transplantation (68). As the injury to the liver in the disease is initiated by changes in the sinusoid, it was renamed SOS (69).

SOS is caused by toxic injury to hepatic sinusoids by pyrrolizidine alkaloid or myeloablative therapy. Major event in the disease is the rounding up or swelling of sinusoidal endothelial cells that results in dissection of the sinusoidal lining, which embolizes and blocks the microcirculation causing sinusoidal hypertension. The disease is characterized clinically by weight gain from sodium retention, hepatomegaly, ascites, and jaundice, and histologically by diffuse damage to centrilobular zone of the liver. Majority of the patients respond to management of sodium and water balance with diuretics and repeated paracentesis (69).

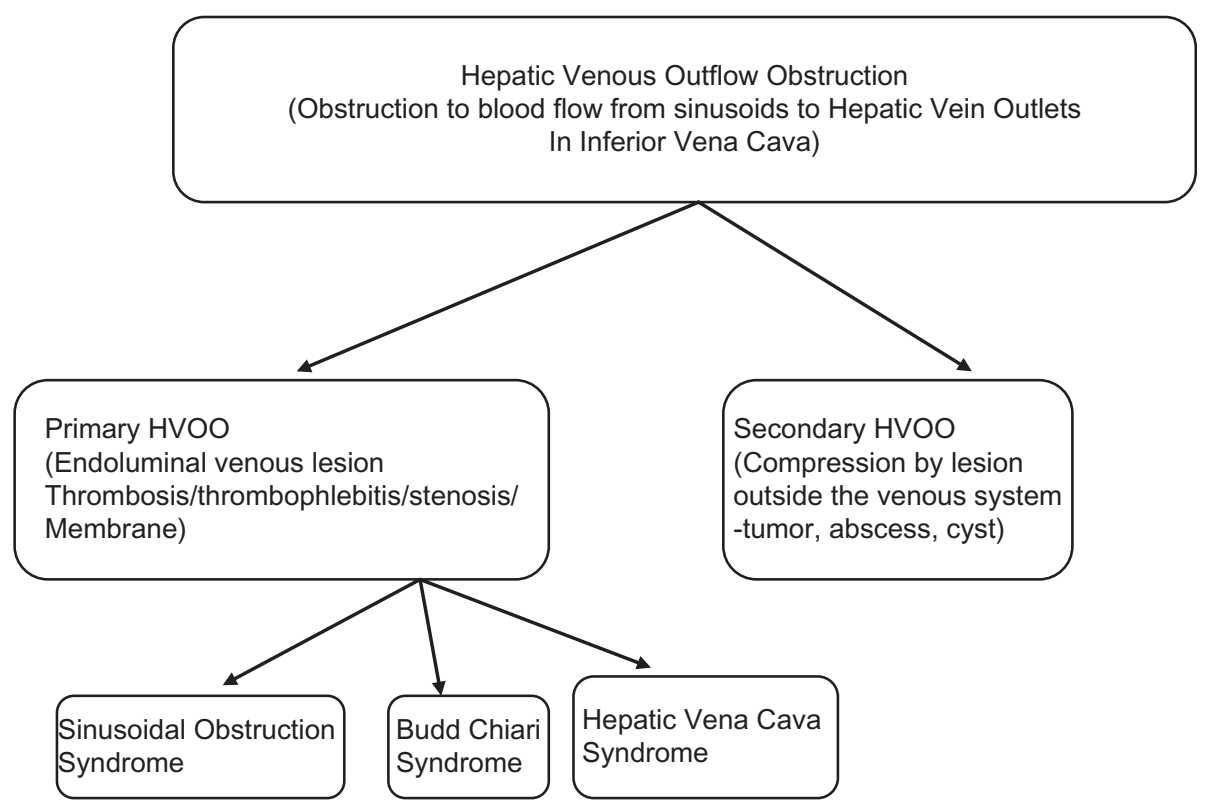

Figure 2. Suggested classification of hepatic venous outflow obstruction. 
Table 1. Three primary diseases of hepatic venous outflow obstruction.

\begin{tabular}{|c|c|c|c|}
\hline Types & $\begin{array}{c}\text { Sinusoidal obstruction } \\
\text { syndrome }\end{array}$ & Budd-Chiari syndrome & Hepatic vena cava syndrome \\
\hline $\begin{array}{l}\text { Primary site of lesion } \\
\text { Secondary site/s }\end{array}$ & $\begin{array}{l}\text { Sinusoidal endothelium } \\
\text { Terminal hepatic vein }\end{array}$ & $\begin{array}{l}\text { Hepatic veins } \\
\text { PV/IVC }\end{array}$ & $\begin{array}{l}\text { Hepatic portion of IVC } \\
\mathrm{HV} \text { ostia/HV/PV }\end{array}$ \\
\hline Etiology & $\begin{array}{l}\text { Toxic injury } \\
\text {-Pyrrolizidine alkaloids } \\
\text {-Immunosuppressive drugs }\end{array}$ & Prothrombotic disorders & $\begin{array}{l}\text { Bacterial infection } \\
\text {-Thrombophlebitis }\end{array}$ \\
\hline Epidemiology & $\begin{array}{l}\text { In person with } \\
\text {-organ transplantation/ } \\
\text {-use of PA containing herbs } \\
\text { Outbreak due to contamina- } \\
\text { tion of wheat with PA } \\
\text { containing seeds }\end{array}$ & Rare & $\begin{array}{l}\text { Endemic in developing } \\
\text { countries }\end{array}$ \\
\hline Clinical & $\begin{array}{l}\text { Acute: hepatomegaly, } \\
\text { ascites, jaundice mild/ } \\
\text { moderate/severe }\end{array}$ & $\begin{array}{l}\text { Acute/subacute/chronic/ } \\
\text { rarely fulminant }\end{array}$ & $\begin{array}{l}\text { Chronic with recurrent acute } \\
\text { exacerbations and cava-caval } \\
\text { collaterals }\end{array}$ \\
\hline Outcome & Spontaneous recovery/LC & $\begin{array}{l}\text { Acute liver failure } \\
\text { Treated with anticoagulant }\end{array}$ & $\begin{array}{l}\text { Respond to treatment with } \\
\text { antibiotic } \\
\text { LC and HCC common }\end{array}$ \\
\hline
\end{tabular}

IVC, inferior vena cava; HV, hepatic vein; PV, portal vein; LC, liver cirrhosis; HCC, hepatocellular carcinoma; PA, pyrrolizidine alkaloid.

\section{Budd-Chiari syndrome}

BCS is a rare disease reported mainly from Western countries. Its prevalence is about $1: 100,000$ populations, with $80 \%$ of the cases occurring in women around 30 years of age. BCS was also reported in India. Myeloproliferative disorders are the most common cause of BCS $(14,29)$. Symptomatic HVT has been observed in $1 \%$ of the patients with primary myeloproliferative disease. Other conditions associated with BCS include antiphospholipid syndrome, paroxysmal nocturnal hemoglobinuria, antithrombin deficiency, protein $\mathrm{S}$ deficiency, protein $\mathrm{C}$ deficiency, and factor $\mathrm{V}$ Leiden. Recently, it has been increasingly recognized that a combination of several thrombogenic conditions and a triggering factor are necessary for the occurrence of HVT (14).

BCS patients with myeloproliferative disorders have, on average, higher platelet counts and a larger spleen. Clinical manifestation depends on the extent and speed of the obstructive process that vary from acute hepatic failure to asymptomatic condition detected fortuitously. BCS with HVOO presents with upper abdominal pain, hepatomegaly, and ascites with moderate alteration of liver tests in persons with known risk factors for thrombosis. US/CD examination is the first choice of investigation. Treatment is aimed at preventing further extension of the thrombosis into other HVs with the use of anticoagulants, and managing complications. For initiating anticoagulation, low-molecular-weight heparins are generally preferred. Depending on the seriousness of the case, the treatment options for BCS include lifelong anticoagulation, angioplasty and stenting, transjugular intrahepatic portosystemic shunt, surgical shunt, or liver transplantation (40). BCS is a disease with well-defined etiology, natural history, and managements.

\section{Hepatic vena cava syndrome}

HVCS is a bacterial infection-induced disease of the hepatic portion of the IVC $(7,70)$. The initial lesion in IVC is a localized thrombophlebitis at the site where HV opens, which on resolution converts the segment into a localized stenosis or complete obstruction. Circulatory balance is maintained by development of many pathways of cava-caval collateral anastomosis (71). The disease is characterized by long asymptomatic period and recurrent acute exacerbations (AEs) precipitated by clinical or subclinical bacterial infection with deposition of fresh thrombus at the site. It is complicated by high incidence of LC and moderate incidence of hepatocellular carcinoma (11). HVCS is a disease of people living in poor hygienic living conditions. It is common in developing countries. It affects people of all ages with high incidence in the second and third decades of life, with a slight increased incidence in males.

The initial lesion or the thrombus formed during severe AE may extend into HV outlets, resulting in $\mathrm{HVOO}$ with sudden development of ascites (Figure 3). Severe AE is likely to develop in persons with poor nutrition or history of alcohol abuse precipitated by puerperal sepsis, chronic bacterial diarrhea, or surgical operation $(72,73)$. Fever and jaundice usually preceded ascites which is associated with neutrophil 


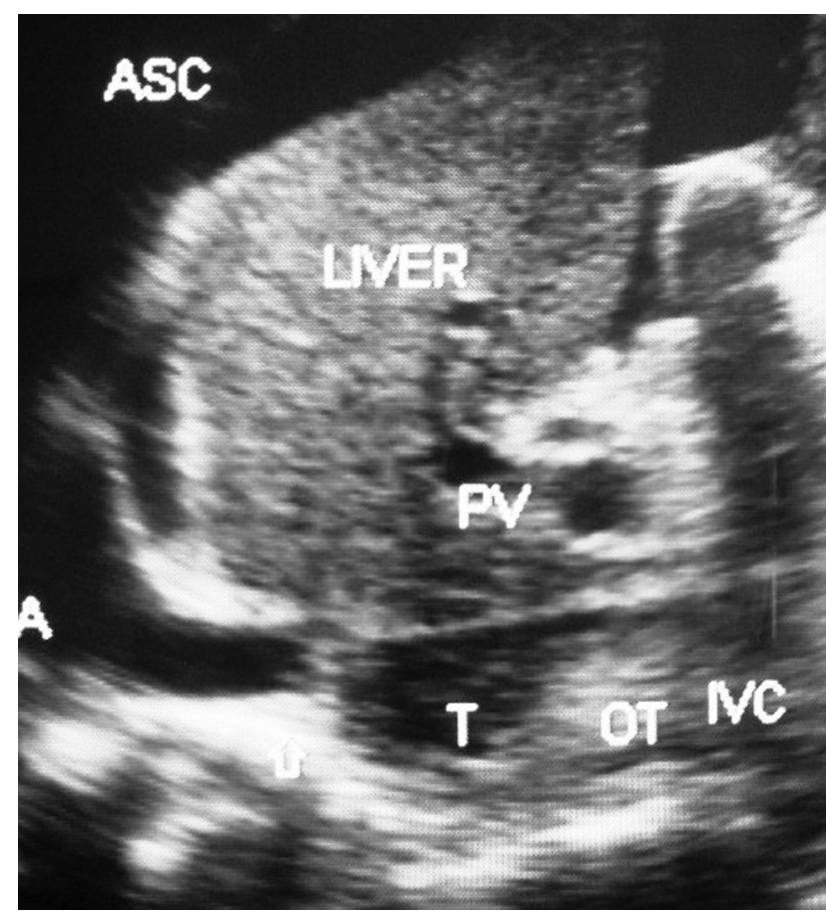

Figure 3. Hepatic vena cava syndrome: Ultrasonography of a young patient with ascites showing localized stenosis of upper segment of IVC with distal dilated segment of the IVC filled with recent and old organized thrombi. ASC, ascites; IVC, inferior vena cava; OT, organized thrombus; RA, right atrium; T, thrombus. (Copyright: Santosh Man Shrestha).

leukocytosis, elevated level of C-reactive protein (CRP), and or bacteremia. Ascites in HVCS is invariably associated with bacterial peritonitis (6). About $15 \%$ of patients develop pleural effusion (74). US/CD examination (75) and laboratory tests that include total and differential white blood cells (WBC), culture of blood and ascitic fluid, and estimation of CRP are diagnostic of ascites from severe acute/AE of HVCS. This condition responds to treatment with high-dose oral antibiotic for 6-8 weeks, salt restriction, and diuretics.

\section{Differential diagnosis of primary diseases of HVOO}

Ascites is an important clinical manifestation of the primary diseases of HVOO. Sudden development of hepatomegaly and ascites with high protein content (usually $>2.5 \mathrm{~g} / \mathrm{dL}$ ), and high serum-ascitic albumin gradient is due to HVOO. SOS is the likely cause when this type of ascites develops in a patient on myeloablative therapy or persons using herbal tea. US/CD shows enlarged liver with no abnormality in $\mathrm{HV}$ and IVC. SOS had occurred as epidemic outbreaks in underdeveloped areas of developing countries, especially during periods of draught. Outbreak of jaundice with ascites in such circumstances indicates to SOS caused by

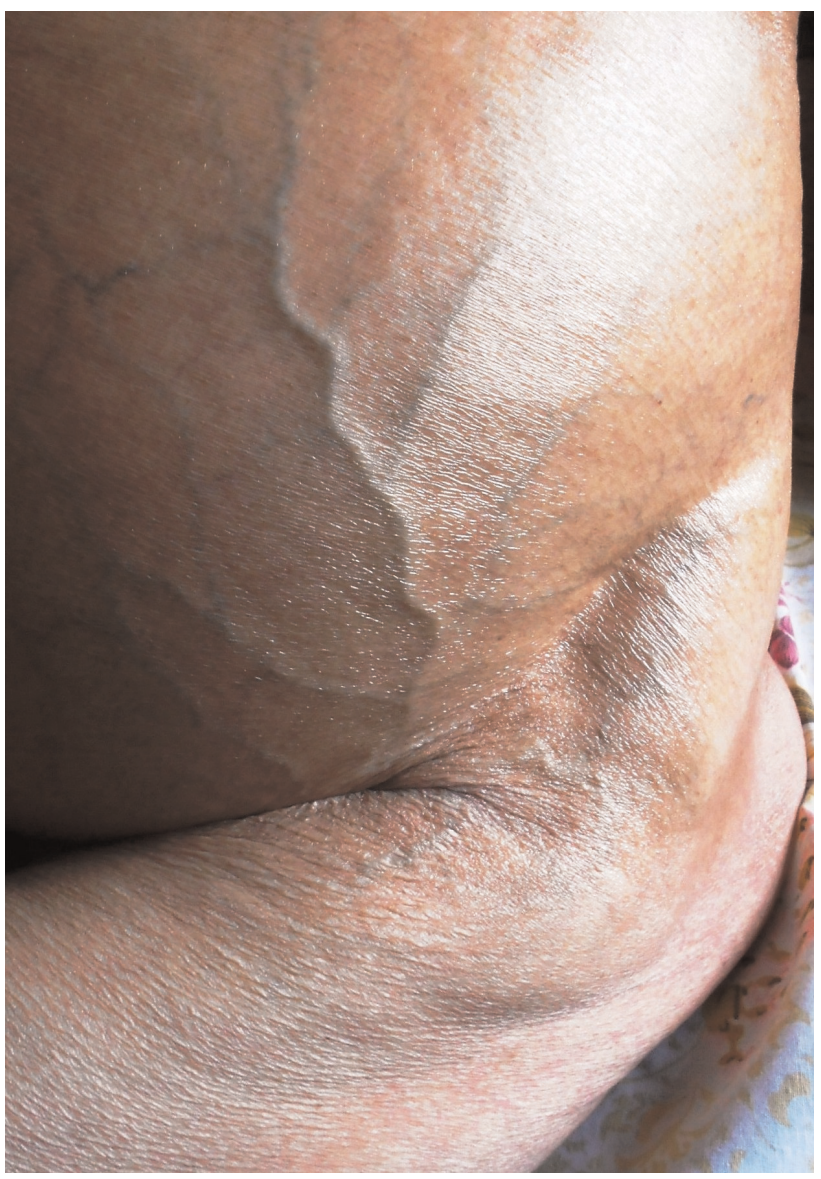

Figure 4. Dilated superficial veins in lower abdomen with upward flow in a patient with chronic HVCS who developed ascites from severe acute exacerbation. Patient had neutrophil leukocytosis and very high level of CRP and ascitic fluid had high protein content, high SAAG, and very high absolute neutrophil count. Patient recovered from treatment with diuretics and antibiotic for 8 weeks. (Copyright: Santosh Man Shrestha).

pyrrolizidine alkaloids. Even dogs in the affected area are known to develop ascites during the outbreak.

HVCS develops in any age group of either sex. Ascites in HVCS is common in persons with poor nutrition or history of alcohol abuse, in whom it is usually precipitated by bacterial infection like puerperal sepsis, chronic diarrhea, and fever or by surgery. Even infants on parenteral nutrition develop this condition. Dilated superficial veins in abdomen with upward blood flow are observed (Figure 4). US/CD examination is diagnostic (75). It shows hepatomegaly and ascites often with evidence of bacterial peritonitis, free-floating particles that settle on standing, acute peritonitis and thick peritoneum with adhesions, loculations, or evidence of perihepatitis indicating chronic peritonitis (Figure 5). Segmental stenosis of medium-sized intra-HVs and prominent main HVs with obstruction to blood flow at the HV outlets will 


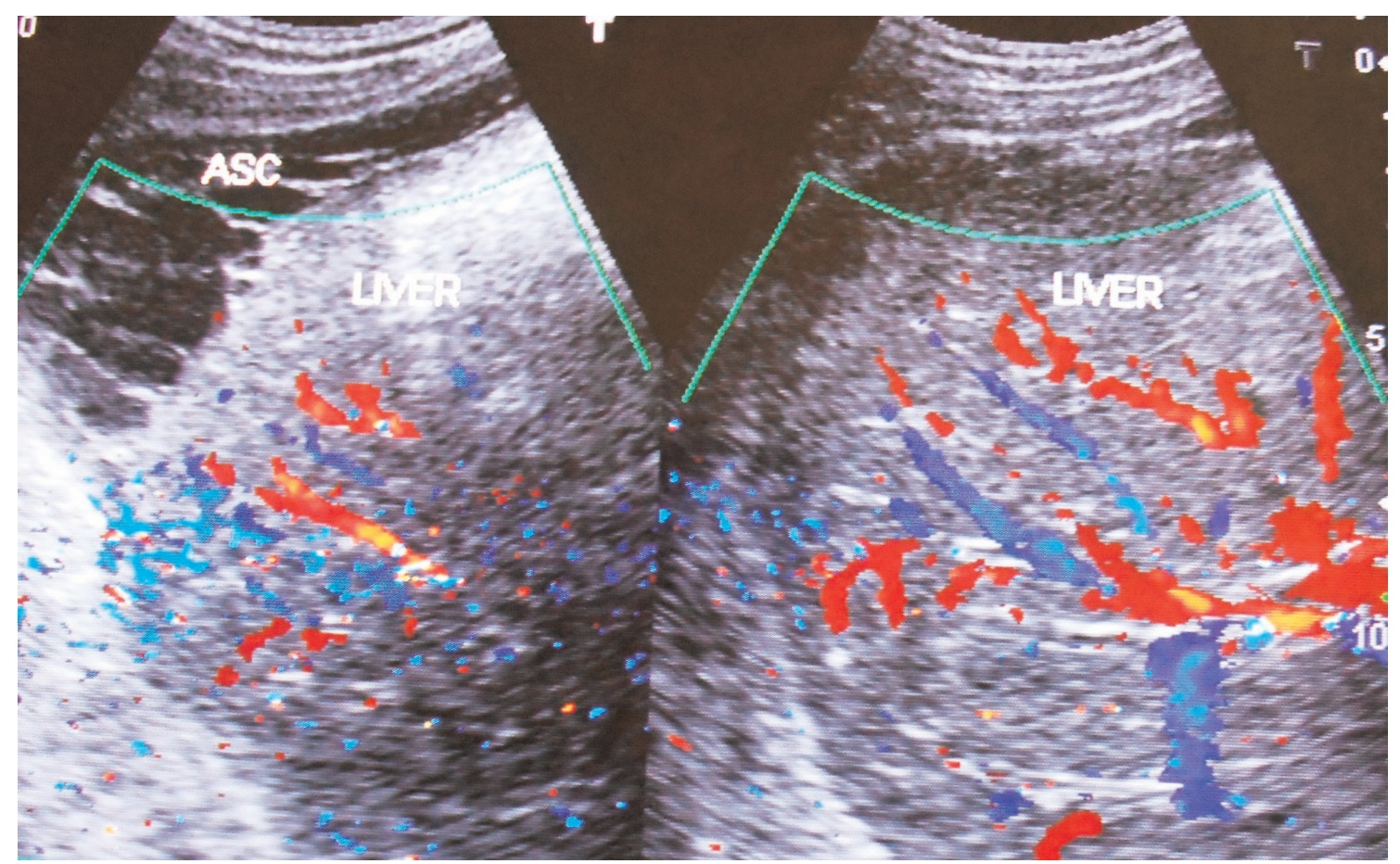

Figure 5. Ultrasonography and color Doppler of a patient with HVCS showing ascites with evidence of chronic peritonitisMultiple intraperitoneal adhesions. Note the thrombosed, medium-sized branches of portal veins. ASC, ascites. (Copyright: Santosh Man Shrestha).

be demonstrated in US/CD. IVC at the site of HV outlet shows stenosis with thick posterior wall with recent and old organized thrombi of different ages along its posterior wall (Figure 6). Gallbladder wall is thick and edematous. Neutrophil leukocytosis or left shift and high level of CRP are common at the onset. Bedside inoculations of blood and ascitic fluid in aerobic blood culture bottle during the initial visit are likely to yield positive culture. Hypersplenism is common in patients with HVCS. Such patients presenting with acute ascites may have normal or slightly elevated WBC count but low platelet count. Levels of serum bilirubin, alanine, and aspartate aminotransferase will be elevated. Cavogram and liver biopsy are not necessary for diagnosis. HVCS patient without ascites usually have normal levels of bilirubin, alanine, and aspartate aminotransferase, but US/CD examination shows IVC with localized stenosis with thick echoic posterior wall in at the level of HV outlet and old organized thrombi along the posterior wall of the distal dilated segment.

Acute onset of high-protein-content ascites in young female patients, especially Caucasians with risk factor for thrombosis, is likely to be due to BCS. BCS patients with myeloproliferative disorders have, on average, higher platelet counts and a larger spleen. US/CD imaging of liver will show features of HV obstruction similar to HVCS, but IVC will be normal or narrowed by caudate lobe enlargement without organized thrombus along its posterior wall, bacterial peritonitis or edematous gallbladder wall.
US and CD imaging should be the first diagnostic tests performed in patients suspected of HVOO. These tests are not only sensitive and specific but also relatively low cost, widely available, and non-invasive with complete lack of harm and minimal technical difficulty. Limitations lie in the patients' body habitus that may preclude complete sonographic evaluation and the lack of experience on the part of the examiner in diagnosis of HVCS. US and CD help in the differential diagnosis of patients presenting with ascites in developing countries when combined with simple laboratory tests such as WBC and platelet counts; CRP, bilirubin, and alanine/ aspartate aminotransferase estimations; ascitic fluid examination for protein, albumin; and bedside culture inoculation in aerobic culture bottle.

In the West, where alcoholic cirrhosis is common, ascites develops late and is considered an indication of hepatic decompensation and liver transplantation. According to Epstein, there is no connection between hepatic decompensation and disturbance in renal sodium handling leading to ascites (76). In developing countries, HVCS is a common comorbid condition in patients with $\mathrm{LC}$ and $\mathrm{HCC}$ related to chronic hepatitis B and C or alcohol (77). Development of ascites in LC patient may be due to severe AE of associated HVCS that responds to medical treatment. Therefore, LC patient in developing countries who develops ascites and jaundice should not straightaway be referred for liver transplantation. 


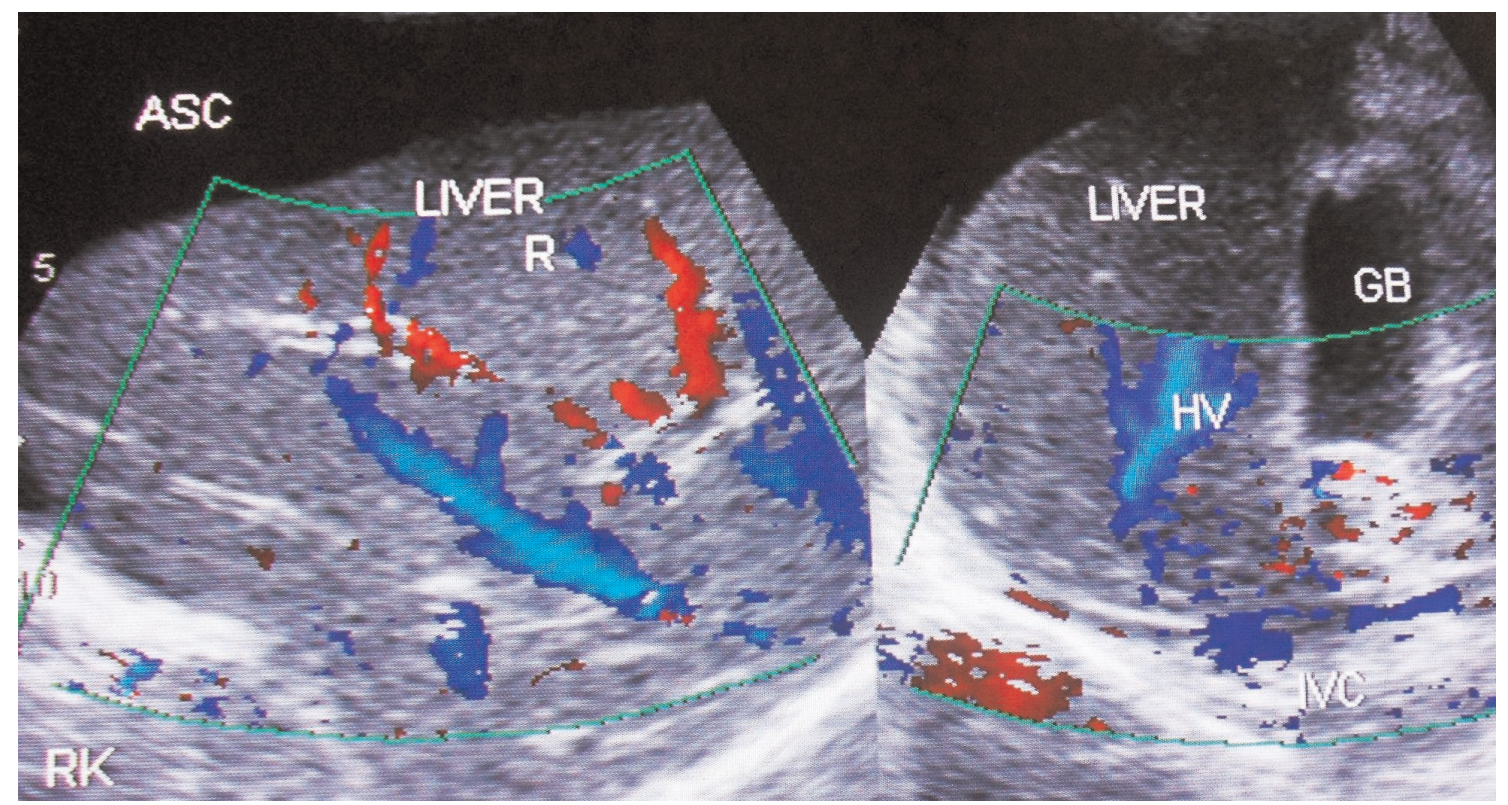

Figure 6. Ultrasonography and color Doppler of a patient with ascites due to HVCS. IVC shows stenosis at cavo-atrial junction with distal segment dilated. IVC is filled with organized thrombus. There is obstruction to blood flow at the hepatic vein outlets. Note thrombosis of medium-sized tributaries of right hepatic vein. GB, gall bladder; HV, hepatic vein; RHV, right hepatic vein. (Copyright: Santosh Man Shrestha).

\section{Conclusion}

HVOO is classified into primary and secondary. Three primary diseases of HVOO are recognized: SOS, BCS, and HVCS. Almost all cases of HVOO seen in clinical practice belong to these three primary diseases. Among these, SOS and BCS are rare and seen exclusively in a particular subset of population: SOS in patients on myeloablative therapy and BCS in young women with hypercoagulable state. HVCS is endemic in developing countries where it is a common cause of ascites and LC.

\section{Conflict of interest}

The author reports no conflict of interest with respect to research, authorship, and/or publication of this article.

\section{References}

1. Bradfield JWB. Liver sinusoidal cells. J Pathol. 1984;142:5-6. http://dx.doi.org/10.1002/path.1711420104

2. Lautt WW. Hepatic vasculature: A conceptual review. Gastroenterology. 1977;73:1163.

3. Greenway CV, Stark RD. Hepatic vascular bed. Physiol Rev. 1971;51:23.

4. Ludwig J, Hashimoto E, McGill DB, Heerden JA. Classification of hepatic venous outflow obstruction: Ambiguous terminology of the Budd-Chiari syndrome. Mayo Clin Proc. 1990;65:51-5. http://dx.doi.org/10.1016/S0025-6196(12)62109-0

5. Arora A, Tandon N, Sharma MP, Acharya SK. Constrictive pericarditis masquerading as Budd-Chiari syndrome. J Clin Gastroenterol. 1991;13(2):178-81. http://dx.doi.org/10.1097/ 00004836-199104000-00012
6. Shrestha SM, Shrestha S. Bacterial peritonitis in the hepatic inferior vena cava disease: A hypothesis to explain the cause of infection in high protein ascites. Hepatol Res. 2002;24:42-9. http://dx.doi.org/10.1016/S1386-6346(02)00018-9

7. Shrestha SM, Kage M, Lee BB. Hepatic vena cava syndrome: New concept of pathogenesis. Hepatol Res. 2017;47(7):603-615. http://dx.doi.org/10.1111/hepr.12869

8. Levy M, Waxler MJ. Sodium excretion in dogs with low-grade caval obstruction: Role of hepatic nerves. Am J Physiol. 1987; 253:F672.

9. Gentil-Kocher S, Bernard O, Brunelle F, Hadchouel M, Maillard JN, Valayer J, et al. Budd-Chiari syndrome in children: Report of 22 cases. J Pediatrics. 1988;113(1):30-8. http://dx.doi. org/10.1016/S0022-3476(88)80524-9

10. Dixon Mann J, Walker Hall I. Obstruction of the inferior vena cava. Edinburgh MJ. 1904;16:56-62.

11. Shrestha SM. Liver cirrhosis and hepatocellular carcinoma in hepatic vena cava disease, a liver disease caused by obstruction of inferior vena cava. Hepatol Int. 2009;3:392-402. http://dx. doi.org/10.1007/s12072-009-9122-5

12. Stuart KL, Bras G. Veno-occlusive disease of the liver. Q J Med. 1957;26:291-315.

13. Stillman AE, Huxtable RJ, Consroe P, Kohnen P, Smith S. Hepatic veno-occlusive disease due to pyrrolizidine poisoning in Arizona. Gastroenterology. 1977;73:349-52.

14. Valla DC. Hepatic vein thrombosis (Budd-Chiari syndrome). Semin Liver Dis. 2002;22(1):5-14. http://dx.doi.org/10.1055/ s-2002-23202

15. Shrestha SM. Liver cirrhosis in hepatic vena cava syndrome (or membranous obstruction of inferior vena cava). World J Hepatol. 2015;7(6):874-84. http://dx.doi.org/10.4254/wjh.v7.i6.874

16. Leopold LG, Parry TE, Storring FK. A change in sinusoidtrabecular structure of the liver with hepatic venous outflow block. 
J Pathol. 1970;100:87-98. http://dx.doi.org/10.1002/path.1711 000203

17. Bolton C, Barnard WG. Pathological occurrences in liver in experimental venous stagnation. J Pathol Bacteriol. 1931;34:701. http://dx.doi.org/10.1002/path.1700340602

18. Kanel GC, Ucci AA, Kaplan MM, Wolfe HJ. A distinctive perivenular hepatic lesion associated with heart failure. Am J Clin Pathol. 1980;73:235-9. http://dx.doi.org/10.1093/ajcp/73.2.235

19. Sherlock S. Liver in heart failure: Relation of anatomical, functional and circulatory changes. Br Heart J. 1951;13:273. http:// dx.doi.org/10.1136/hrt.13.3.273

20. Chiari H. Ueber die selbstandie Phlebitis obliteraqns der Hauptstamme der Venae hepaticae als Todesursache. Beitr Z Pathol Anat U Z Allg Pathol. 1899;26:1-18.

21. Parkar RGF. Occlusion of the hepatic veins in man. Medicine. 1959;38:369-402. http://dx.doi.org/10.1097/00005792-19591200000002

22. Tanaka M, Wanless IR. Pathology of the liver in BuddChiari syndrome: Portal vein thrombosis and histogenesis of veno-centric cirrhosis, veno-portal cirrhosis and large regenerative nodules. Hepatology. 1998;27:488-96. http://dx.doi.org/ 10.1002/hep.510270224

23. Kage M, Arakawa M, Kojiro M, Okuda K. Histopathology of membranous obstruction of the inferior vena cava in the BuddChiari syndrome. Gastroenterology.1992;102:2081-90. http:// dx.doi.org/10.1016/0016-5085(92)90336-W

24. Chawla YK, Bodh V. Portal vein thrombosis. J Clin Exp Hepatol. 2015;5(1):22-40. http://dx.doi.org/10.1016/j.jceh.2014.12.008

25. McCuskey RS. Morphological mechanisms for regulating blood flow through hepatic sinusoids. Liver. 2000;20:3-7. http://dx.doi. org/10.1034/j.1600-0676.2000.020001003.x

26. Janssen HLA, Gaecia-Pagan J-C, Elias E, Mentha G, Hadengue A, Valla D-C. Budd-Chiari syndrome: A review by an expert panel. J Hepatol. 2003;38:364-71. http://dx.doi.org/10.1016/ S0168-8278(02)00434-8

27. Valla DC. Budd-Chiari syndrome. In: Boyer TD, Wright TL, Manns MP, editors. Zakim and Boyer hepatology-Textbook of liver diseases. Philadelphia, PA: Saunders; 2006. p. 877-96.

28. Plessier A, Valla DC. Budd-Chiari syndrome. Semin Liver Dis. 2008;28:259-69. http://dx.doi.org/10.1055/s-0028-1085094

29. DeLeve LD, Valla CD, Garcia-Tsao G. Vascular disorders of the liver. AASLD practical guidelines. Hepatology. 2009;49(5): 1729-63. http://dx.doi.org/10.1002/hep. 22772

30. Okuda K. Membranous obstruction of the inferior vena cava (obliterative hepatocavopathy, Okuda). J Gastroenterol Hepatol. 2001;16:1179-83. http://dx.doi.org/10.1046/j.1440-1746. 2001.02577.x

31. Budd G. Disease of the liver. London: John Churchill; 1845.

32. Raynaud. J hebd Med, Paris 1827; 5:173. Quoted by: Pleasants $\mathrm{JH}$. Obstruction of inferior vena cava with a report of 18 cases. Johns Hopkins Hosp Rep. 1911;16:363-548.

33. Wilks S. Obstruction of hepatic veins and vena cava by fibrous deposit in the liver. Trans Path Soc Lond. 1862;13:122-4.

34. Osler W. Case of obliteration of vena cava inferior, with great stenosis of the orifices of hepatic veins. J Anat Physiol. 1878; 13:291-305.

35. Valla D-C. Hepatic venous outflow obstruction etiopathogenesis: Asia versus the West. J Gastroenterol Hepatol. 2004;19:S204-11. http://dx.doi.org/10.1111/j.1400-1746.2004.03642.x

36. Dilawari JB, Bambery P, Chawla Y, Kaur U, Bhusnurmath SR, Malhotra HS, et al. Hepatic outflow obstruction (Budd-Chiari syndrome). Experience with 177 patients and a review of literature.
Medicine. 1994;73:21-36. http://dx.doi.org/10.1097/00005792199401000-00003

37. Singh V, Sinha SK, Nain CK, Bambery P, Kaur U, Verma S, et al. Budd-Chiari syndrome: Our experience of 71 patients. J Gastrotenterol Hepatol. 2000;15:550-4. http://dx.doi.org/ 10.1046/j.1440-1746.2000.02157.x

38. Wang ZG, Zhang FJ, Li XQ, Meng QY. Management of BuddChiari syndrome: What is the best approach? J Gastroenterol Hepatol. 2004;19(Suppl):S212-18. http://dx.doi.org/10.1111/j.14401746.2004.03677.x

39. Valla D, Hadengue A, el Yoounsi M, Azar N, Zeitoun G, Boudet MJ, et al. Hepatic venous outflow block caused by short-length hepatic vein stenosis. Hepatology. 1997;25:814-19. http://dx.doi.org/10.1002/hep.510250405

40. Murad SW, Valla D-C, de Groen PC, Zeitoun G, Hopmans JAM, Haagsma EB, et al. Determinants of survival and effect of portosystemic shunting in patients with Budd-Chiari syndrome. Hepatology. 2004:39:500-8. http://dx.doi.org/10.1002/hep.20064

41. Tandon BN, Nundy S. Outflow tract obstruction. In: Textbook of tropical gastroenterology. Delhi: Oxford University Press; 1988. p. 183-91.

42. Chawla YK. Budd-Chiari syndrome. In: Mahatab MA, Rahman S, editors. Liver: A complete book on hepato-pancreato-biliary diseases. India: Elsevier; 2009. p. 381-5.

43. Shrestha SM, Shrestha S. Hepatic vena cava syndrome: A common cause of liver cirrhosis in children in Nepal. Trop Gastroenterol. 2014;35(2):85-95. http://dx.doi.org/10.7869/tg.186

44. Nakamura T, Nakamura S, Aikawa T, Suzuki O, Onodera A, Karoji N. Obstruction of the inferior vena cave in the hepatic portion and the hepatic veins: Report of eight cases and review of the Japanese literature. Angiology. 1968;19:479-98. http:// dx.doi.org/10.1177/000331976801900805

45. Yamamoto S, Yokoyama Y, Takeshige K, Iwatsuki S. BuddChiari syndrome with obstruction of the inferior vena cava. Gastroenterology. 1968;54:1070-84.

46. Takeuchi J, Takada A, Hasumura Y, Matsuda Y, Ikegami F. Budd-Chiari syndrome associated with obstruction of the inferior vena cava. Am J Med. 1971;51:11-20. http://dx.doi.org/ 10.1016/0002-9343(71)90319-6

47. Nakamura S, Takezawa Y. Obstruction of the inferior vena cava in the hepatic portion and hepatocellular carcinoma. Tohoku J Exp Med. 1982;138:119-20. http://dx.doi.org/10.1620/tjem. 138.119

48. Datta DV, Saha S, Singh SA, Gupta BB, Aikat BK, Chutani PN. Clinical spectrum of Budd-Chiari syndrome in Chandigarh with particular reference to obstruction of intrahepatic portion of inferior vena cava. Indian J Med Res. 1972;60:385-401.

49. Madangopalan N, Solomon V, Jayanthi V, Raghuram K, Balakumar M, Kandasamy I, et al. Clinical spectrum of chronic Budd-Chiari syndrome and surgical relief for "coarctation" of the inferior vena cava. J Gastroenterol Hepatol. 1986;1:359-69. http://dx.doi.org/10.1111/j.1440-1746.1986.tb00776.x

50. Shrestha SM. Membranous obstruction of hepatic portion of the inferior vena cava: Is this an underdiagnosed entity in developing countries. Am J Gastroenterol. 1995;90(2):303-6.

51. Shrestha SM, Okuda K, Uchida T, Maharjan KG, Shrestha S, Joshi BL, et al. Endemicity and clinical picture of liver disease due to obstruction of the hepatic portion of the inferior vena cava in Nepal. J Gastroenterol Hepatol. 1996;11:170-9. http:// dx.doi.org/10.1111/j.1440-1746.tb00056.x

52. Shrestha SM. Hepatic venous outflow obstruction in Nepal. Trop Gastroenterol. 1996;17:165-71. 
53. Simson IW. Membranous obstruction of the inferior vena cava and hepatocellular carcinoma in South Africa. Gastroenterology. 1982;82:171-8.

54. Kew MC, McKnight A, Hodkinson J, Bukofzer S, Esser JD. The role of membranous obstruction of the inferior vena cava in the etiology of hepatocellular carcinoma in Southern African Blacks. Hepatology. 1989;9:121-5. http://dx.doi.org/10.1002/hep. 1840090121

55. Awwad S. The Budd-Chiari syndrome. Egypt Med J. 1952;35: 650-69.

56. Kimura C, Matsuda S, Koie H, Hirooka M. Membranous obstruction of the hepatic portion of the inferior vena cava: Clinical study of nine cases. Surgery. 1972;72:551-9.

57. Ono J, Sakoda K, Kawada T. Membranous obstruction of the inferior vena cava. Ann Surg. 1983;197:454-8. http://dx.doi. org/10.1097/00000658-198304000-00014

58. Wang Z-G. Management of Budd-Chiari syndrome: Experience from 430 cases. Asian J Surg. 1996;19:23-30.

59. Lee B-B, Villavicencio L, Kim YW, Do YS, Koh KC, Lim HK, et al. Primary Budd-Chiari syndrome: Outcome of endovascular management for suprahepatic venous obstruction. J Vas Surg. 2006;43(1):101-8. http://dx.doi.org/10.1016/j.jvs.2005.09.003

60. Okuda K, Kage M, Shrestha SM. Proposal of a new nomenclature for Budd-Chiari syndrome: Hepatic vein thrombosis versus thrombosis of the inferior vena cava at its hepatic portion. Hepatology. 1998;28:1191-8. http://dx.doi.org/10.1002/ hep. 510280505

61. Shrestha SM. Natural history of hepatic vena cava disease, the liver disease due to obstruction of hepatic portion of inferior vena cava. Hepatol Int. 2009;3:1-12. http://dx.doi.org/10.1007/ s12072-009-913-2.

62. Bras G, Jeliffe DB, Stuart KL. Veno-occlusive disease of the liver with non-portal type of cirrhosis occurring in Jamaica. Arch Pathol. 1954;57:285-300.

63. Dubrovinskii SB. The etiology of toxic hepatitis with ascites. In: Millenkov SM, Kizhaikin Y, editors. Collection of scientific papers on toxic hepatitis with ascites. Tashkent, USSR: Publishing House of the University of Central Asia; 1952. p. 9-25.

64. Mohabbat O, Younos MS, Merzad AA, Srivastava RN, Sediq GG, Aram GN. An outbreak of hepatic veno-occlusive disease in north-western Afghanistan. Lancet. 1976;2:269-71. http://dx. doi.org/10.1016/S0140-6736(76)90726-1

65. Tandon RK, Tandon BN, Tandon HD, Bhatia ML, Bhargava S, Lal P, et al. Study of an epidemic of veno-occlusive disease in India. Gut. 1976;17:849-55. http://dx.doi.org/10.1136/gut.17.11.849
66. Tandon HD, Tandon BN, Nayak NC. A pathological study of liver in an epidemic outbreak of veno-occlusive disease. Indian J Med Res. 1977;65:679-84.

67. Read AE, Weisner RH, LaBrecque DR, Tifft JG, Mullen KD, Sheer RL, et al. Hepatic veno-occlusive disease associated with renal transplantation and azathioprine therapy. Ann Intern Med. 1986;104:651-5. http://dx.doi.org/10.7326/0003-4819-1045-651

68. Berk PD, Popper H, Krueger GRF, Decter J, Herzig G, Graw RG Jr. Veno-occlusive disease of the liver after allogeneic bone marrow transplantation. Ann Intern Med. 1979;90:158-64. http://dx.doi.org/10.7326/0003-4819-90-2-158

69. DeLeve LD, Shulman HM, McDonald GB. Toxic injury to hepatic sinusoids: Sinusoidal obstruction syndrome (veno-occlusive disease). Semi Liver Dis. 2002;22:27-41. http://dx.doi.org/ 10.1055/s-2002-23204

70. Shrestha SM, Shrestha S. Hepatic vena cava disease: Etiologic relation to bacterial infection. Hepatol Res. 2007;37:196-204. http://dx.doi.org/10.1111/j.1872-034X.2007.00012.x

71. Pleasants JH. Obstruction of inferior vena cava with a report of 18 cases. Johns Hopkins Hosp Rep. 1911;16:363-548.

72. Khuroo MS, Datta DV. Budd-Chiari syndrome following pregnancy. Am J Med. 1980;68:113-21. http://dx.doi.org/10.1016/ 0002-9343(80)90180-1

73. Shrestha SM, Ghimire RK, Basnyat P, Pradhan V, Poudel V. Acute on chronic phenomenon in hepatic IVC obstruction: A case report. Trop Gastroenterol. 1999;20:182-4.

74. Shrestha SM. Pleural effusion in hepatic vena cava disease. Kathmandu University Med J. 2007;5(2):218-24.

75. Shrestha SM. Diagnosis of hepatic vena cava syndrome by ultrasonography and color Doppler based on new concept of its pathogenesis. EC Gastroenterol Dig Syst. 2017;2(1): 256-70.

76. Epstein M. Functional renal abnormalities in cirrhosis: Pathophysiology and management. In: Zakim D, Boyer TD, editors. Hepatology a textbook of liver disease. 2nd ed. Vol. I. Philadelphia, PA: W.B. Saunders; 1990. p. 493-512.

77. Shrestha SM, Shrestha S, Shrestha A, Tsuda F, Endo K, Takahashi M, et al. High prevalence of hepatitis B virus infection and inferior vena cava obstruction among patients with liver cirrhosis or hepatocellular carcinoma in Nepal. J Gastroenterol Hepatol. 2007;22:1921-8. http://dx.doi.org/10.1111/j.1440-1746. 2006.04611.x 